Binghamton University

The Open Repository @ Binghamton (The ORB)

The Society for Ancient Greek Philosophy Newsletter

1957

\title{
A Zenonian Argument against Plurality
}

Gregory Vlastos

Follow this and additional works at: https://orb.binghamton.edu/sagp

Part of the Ancient History, Greek and Roman through Late Antiquity Commons, Ancient Philosophy Commons, and the History of Philosophy Commons

\section{Recommended Citation}

Vlastos, Gregory, "A Zenonian Argument against Plurality" (1957). The Society for Ancient Greek Philosophy Newsletter. 18.

https://orb.binghamton.edu/sagp/18

This Article is brought to you for free and open access by The Open Repository @ Binghamton (The ORB). It has been accepted for inclusion in The Society for Ancient Greek Philosophy Newsletter by an authorized administrator of The Open Repository @ Binghamton (The ORB). For more information, please contact ORB@binghamton.edu. 


\author{
A Zenonian Argument Against Plurality. ${ }^{1}$
}

The two surviving fragments of this argument make up between them some $75 \%$ of all that has come down to us of Zeno's original treatise. On this one ground, if on no other, they have a high claim on the attention of anyone interested in becoming acquainted with the authentic Zeno. The problems they present are great but, one may hope, not insuperable. How much progress has already been made one may judge by comparing the best of the recent studies, Fraenkel's, 2 with the best of the older ones, Zeller's. 3 The present study picks up where Fraenkel's leaves off, and this may help explain why it devotes so much more space to the discussion of his views than to those of other scholars.

\title{
(I) Reconstruction of $\mathrm{Sl}$.
}

Simplicius, I.I to whom we owe the preservation of our two fragments ("BI" and "B2", I shall call them hereafter, by their numbering in DielsKranz) I.2 makes it clear that they formed parts of a longer train of argument. I.3 Of this our BI was the concluding section, being preceded (contrary to Diels' mistaken numbering) by our B2. This in turn was preceded by another argument, which I shall call, arbitrarily, "Sl." Here Simplicius (139.18-19) tells us -- and this is all he says about it - Zeno had "previously [i.e., prior to B2] demonstrated that nothing has size due to each of the many (existents) being self-identical and one:" Though only a paraphrase, and an incomplete one, this is entitled to respect, for it is written by a man who has an original text I. 4 not far from his eyes, having just cited from it verbatim our B2, and about to cite shortly after our BI. So taking our stand on Simplicius: paraphrase -- the deduction of absence of size from self-identity and unity -- we can proceed to look for the other premises which would have authorized this surprising inference. Now it so happens that we have a fragment of Melissus (B9), where absence of size is inferred from unity. I translate literally, and number the sentences for convenient reference:

[MI] "If it exists, I.5 it must be one;

[M2] but if it is one, it must have no body.

[M3] But if it had thickness, it would have parts,

[M4] and then it would not be one.

Now by pasting the data of Simplicius' paraphrase on this fragment of Melissus we can produce the following reconstruction of Sl:

[Zl] If anything exists, it must be one and self-identical.

[Z2] But if it is one and self-identical, it must have no size.

[Z3] For if it had size, it would have parts,

$[\mathrm{Z4}]$ and then it would not be one and self-identical.

[Z5] Thus, if the many exist, none of them can have size.

This is a sufficient solution to the problem of supplementing the data in Simplicius with premises that would be quite acceptable to an Eleatic yet still so plausible in themselves that assent to them could be elicited from non-Eleatics by easy supporting moves: e.g., for [z3], 'If it has any size at all, it must be two halves of that, four quarters of it, and so forth'; and for [ $[4]$, 'If it has two parts, then it is two things, hence no longer one, I.6 and then how could it be the same as itself, since it is one?" 
The main hazard of the reconstruction is obviously at [z3], [Z4], which fill in a middle term for the inference certified by Simplicius: from unity and self-identity to absence of size. Can we get some independent confirmation of this suggestion? It seems that we can, for a part of it, i.e. for Zeno's arguing, as did Melissus, from the (supposed) incompatibility of ' $x$ is one' with ' $\underline{x}$ has parts' and the entailment of ' $x$ has no size' by ' $x$ has no parts': "Alexañder says that the second argument, the one from dichotomy, Arist., Phys. 187a 1-2,], is Zeno's, who argues that if being had size and were divisible, it would be no longer one but many..." I.7 Since "divisible" here = 'has parts', I.8 this is good support for this part of the reconstruction. Its confirmatory value would not be appreciably reduced if, as seems probable, Alexander was echoing here not SI as such but a part of another of Zeno's arguments against plurality. I.9 There would be nothing to keep Zeno from using some of the same materials in different arguments. I.IO

\section{(II) The Argument of B2.}

As cited by Simplicius (139.10-11), the demonstrandum was: "That which has neither size nor thickness nor mass, would not even exist;" III.I the proof ran:

[1] For if it were attached II.2 to another existent, it would make (the latter) no larger.

[2] For, having no size, it can contribute nothing in respect of size when attached.

[3] And thus (it follows) already that what is attached would be nothing.

[4] If, indeed, something will not decrease another by detachment from it, nor increase it by attachment to it, it is clear that what was attached or detached was nothing."

As is clear at [3], and also at [4], Zeno, in good Eleatic fashion, takes "would be nothing" as equivalent to "would not exist" in the demonstradum. II.3 Let us give him this equivalence: we have more pressing things to worry about. What is to be proved is, "If $x$ has no size, $x$ is nothing. "The supposed proof: 'If $x$ has no size, it can add none to $\underline{y}$ by attachment to $\underline{y}(=[2])$, hence cannot increase $\mathrm{y}_{\mathrm{y}}(=[1])$, hence is nothing $(=[3])$.' But this last step is astonishing. How could one possibly infer 'is nothing' from 'cannot increase $\mathrm{y}^{\text {'? }} \mathrm{All}$ one could infer from the latter is 'is nothing in respect of size', $\bar{i}$.e. 'has no size." But this we already know as the hypothesis at [2] and [1]. Could it then be that Zeno has confused ' $\mathrm{x}$ has no size' with ' $\mathrm{x}$ is nothing'? Impossible. These two propositions are, respectively, equivalent to the antecedent and consequentII.4in the demonstrandum. Unless they were perfectly distinct in Zeno's mind there would have been no argumment. What could be happening then? Could it be trickery? Fraenkel (pp. $20 \mathrm{ff.}$ ) has so argued: The phrase at [3] which I have

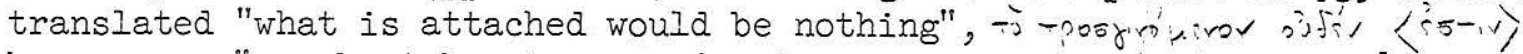
he argues, "can be taken to mean 'no increase takes place'..., or [alternatively] "that which is added is nothing", and Zeno is counting on getting the phrase with the vital, second sense past the reader's defences by having it slip by in the innocent, first sense. Is Zeno then a slippery character, a sophist? Let us not get drawn into this argument, but only ask how effective the suggested trick would really be. ressfrof -j had been used just before, at [3], to mean quite unambiguously (in the usual translation) "that (existent) which is added." Why should the reader (unless he were half asleep when he read that sentence) be expected now, one sentence later, to take the very same word in the different sense of "the increase'? But suppose he did; then he would know (unless he is still nodding) that

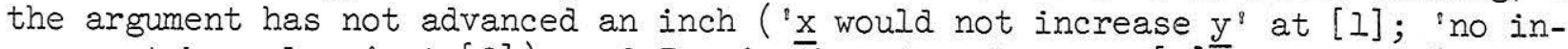

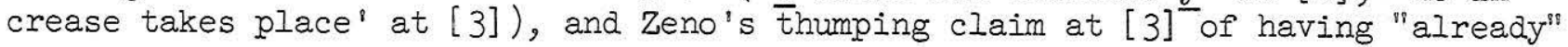


proved the essential point would be inane. A reader who could be fooled by such a manoeuvre would scarcely be worth fooling.

I wish to suggest another way of construing the argument. Suppose we were to take 'If [1], then [3]' as an enthymeme. What would be the missing premise? Obviously

[0] That which would not increase another by attachment to it, or decrease it by detachment from it, would be nothing.

Given this as the major, and [I] as the minor, [3] would follow smoothly. II.4 And if we now look at [4] above, it will be evident, I trust, that it is only verbally different from [0]. Zeno's argument then becomes formally correct if we take it as follows: 'If [2], then [1]; and [1], given [4], implies [3].' What may occasion suprise is that [4] should then be left to bring up the rear, instead of heading the procession or, in any case, preceding [3]. II.5 But this reversal of the formal order is done often enough in a conversational argument. Cf. 'A and B must be equal, for they are both right angles. It is clear, I take it, that all right angles are equal.' A similar reversal in Zeno's argument would incur no fault of inference, nor would it break any rules of exposition, for there were none to break at this time and for a long time after. The more serious question would be whether Zeno is entitled to [0] as a premise. Since this is clearly a dialectical argument, this question boils down to: Is [0] the sort of premise that Zeno's readers would have passed as unquestioningly true? Were it not for the conclusion of the immediately preceding Sl, the answer would surely be: 'Yes; no one would think of disputing [0], except one who had already formed the notion of incorporeal existence, and this could not be claimed for anyone prior to the Eleatics.' But now that Zeno has just finished proving to the reader that no existent has size, it does seem awkward to expect him to admit a proposition which so obviously contradicts that conclusion. An alert reader might have balked at this point, retorting: 'You are asking me to assume [0], having already implied it is false.' But Zeno could have replied: 'You have been assuming it long before this argument began. Are you so fully persuaded now of the conclusion of Sl that you are prepared to surrender all of your previous beliefs that will not square with it? If so, I welcome you as a brother in the Eleatic faith, and there is no need of further argument with you. It is only the unconverted I am addressing now, who have not yet taken stock of the effect of the preceding argument on their familiar dogmas, [0] among them. Their innocence serves my purpose. By letting them keep [0] for the time being, I can set off another explosion whose blast effect should be still greater on their stolid minds.'

Certainly Zeno would have produced a more elegant argument had he denied himself after SI the use of any premise which clashes directly with the conclusion of Sl. The beauty of his other extant fragment against plurality, B3, is that it achieves just this effect. His performance here is definitely clumsier by contrast. II.6 But it is still a tolerable form of dialectical argument and this, I submit, is a sufficient reason for acceptingthis interpretation of his text in preference to either of the above alternatives which involve, respectively, confusion and deception. 
(III.) Bl: Translation and Explanation.

\section{Translation}

1. But if [the many] III.I exist, each must have some size and thickness, and one [part] of each III.2 must extend beyond the other [part of the same existent].

2. And the same reasoning applies to the projecting [part]. For this too will have size and some [part] of it will project.

3. Now to say this once is as good as saying it for ever: For no such [projecting part] of it will be the last or without one [part similarly] related to the other [part].

4. Thus if there are many, they must be both small and large: so small as not to have size; so large as to be infinite.

\section{Analytic Paraphrase}

1. If $[P]$, then $[Q]$, and then $[R]:$ III.3

[P] There are many existents.

[Q] Every existent has size.

[R] Given any existent, $\underline{a}$, there will be two existents, $\underline{b}$ and $\underline{c}$, which are non-overlapping parts of $\underline{\text { a. }}$

2. If $[Q]$, then also $[S]$ :

[S] Given $\underline{c}$, there will be two existents, $\underline{a}$ and $\underline{e}$, non-overlapping parts of $\underline{c}$.

3. If $[R]$ and $[S]$, then $[T]$ :

[T] The series $\underline{a}, \underline{c}, \underline{e}, \underline{g}, \ldots$ whose every term is related to its predecessor as $\underline{c}$ to $\underline{a}$, has no last term.

4. If [P] (and ???), III.4 then [U] and [not-U]:

[U] The size of a is null.

[not-U] The size of a is infinite.

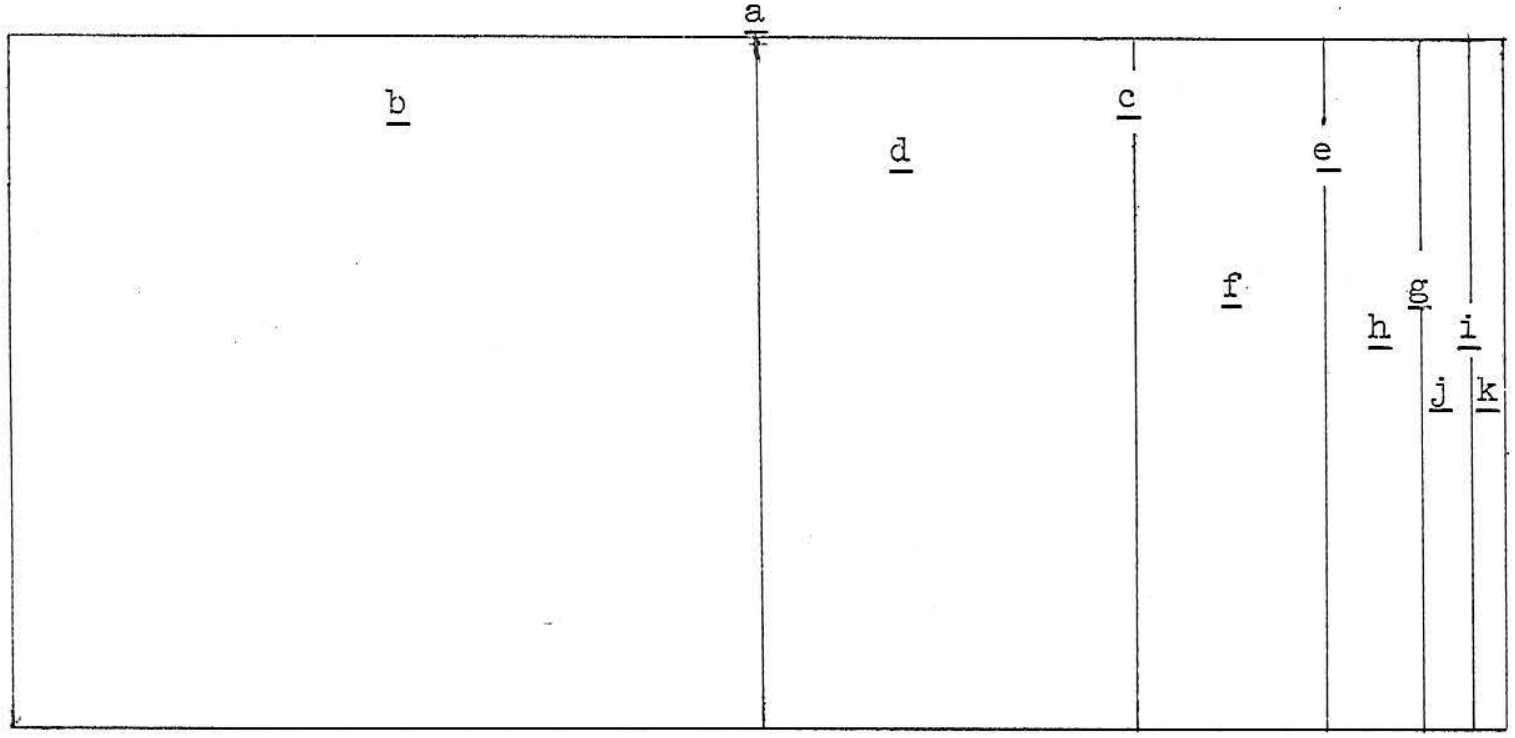


There have been two broadly different constructions III.5 of the reasoning

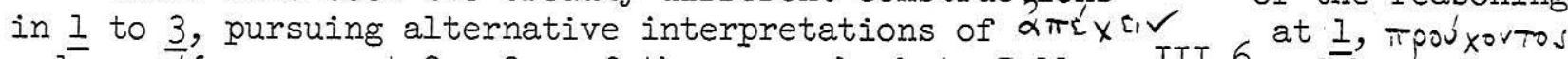
and -posks at 2 . One of them goes back to Zeller. III.6 and has enjoyed the support of excellent scholars, notably Fraenkel's, III.7 who translates a $\mathcal{L}^{\prime} \times \mathcal{L}_{1} \mathrm{~V}$ "to be at a distance from", and takes the sense to be: two parts, front and back, are separated by an intervening core. In that case my [R] would have to be re-written as

$\left[R^{\prime}\right]$ Given any existent, $\underline{a}$, there will be three existents, $\underline{b}, \underline{m}$, and $\underline{c}$, which are non-overlapping parts of $\underline{a}$, and such that $\underline{b} \bar{i}$ separated from $\underline{c}$ by $\underline{m}$.

Similarly my [S] would have to be re-written as

[S:] Given $\underline{c}$, there will be three existents, $\underline{a}, \underline{n}$, and $\underline{e}$, non-overlapping parts of $\underline{c}$, such that $\underline{a}$ is separated from $\underline{e}$ by $\underline{n}$.

My $[\mathrm{T}]$, on the other hand, would be unaffected: this, no more and no less, would be inferred from [ $\left.R^{\prime}\right]$ and $\left[S^{\prime}\right]$, as from $[R]$ and [S]. This is my main objection to Fraenkel's interpretation: Why should Zeno use more elaborate machinery to get his [T] when a simpler one would suffice?. As for the wording, it is (at the least) compatible with the more economical construction, in that it refers to two parts at the first division, with no allusion to an intervening third III.8 at 1 or thereafter: $\underline{2}$ (and, by implication, $\underline{3}$ ) refers only to the "projecting" part; and $\pi p o c^{\prime} \times \varepsilon_{1} v$, in its standard sense, 'project, jut out from,' is normally said of contiguous parts, one of which is thought of as sticking out from or extending beyond the other; III.9 the same sense is possible, though not standard, for a.rćxiv, whose meaning in I must in any case be the same as that of $\pi$ poúxovtos at 2 .' III.IO

Now we can see how the argument goes. That [P] implies [Q] is a carryover from B2. That [Q] implies [R] takes us back to. [M3] and [Z3] at Section (I) above. One may conjecture that the reasoning would be: if something has bulk, it must be spread out in space, so you can distinguish in it a 'here: from a 'there'; having such contiguous, non-coincident and non-overlapping, parts or regions, Zeno, might have explained, is part of what we mean by having size. The discrimination of any two such parts in any existent I shall refer to as a 'division,' though no such word appears in Zeno's text, III.II or even in my analytic paraphrase. It will be simply a convenient name for the process by which we get the two parts, $b$ and $c$, at $1, d$ and $e$ at 2 , or any subsequent two thereafter. III.12 That no physical cut or fission is intended here is quite obvious, and none would have been warranted anyhow, without further assumptions, since no property of existents except their size is specified at [Q]. Thus the problem, insoluble for the engineer, of pursuing the division past the smallest particle he can split with his present tools, does not arise. That no part reached by such division will be the last follows by reiteration of the reasoning which warrants [R] and [S] or even analytically from [R] alone: a supposed last term in the $a, \underline{c}, \underline{e}, \underline{g}, \ldots$ series would have to be an existent (since only existents are members of the series), yet not have the two parts prescribed by [R] for any existent.

\section{(IV) The Deduction of Nullity of Size.}

How get past [T] to the dilemma in the conclusion? The answer must have seemed obvious to Zeno, since he gives not a word to justify, or even outline, 
the transit. IV.l But what would he have said, if pressed for an explanation? Let us start with the first part of the contradiction which, he thinks, he has proved to follow from the refutandum: "Thus if [P] there are many, than [U] they must be... so small as not to have size." Is [U] supposed to follow from the preceding argument in Bl? Or is it meant as the consequence of something or other before Bl? Here are two possible justifications of [U]: ' $j I$ ' and ' $j I I '$, let us call them. Offhand, the first might seem the better bet, for one would ordinarily expect [U] to be the direct upshot of the close-packed argument which immediately precedes it. It has been so taken by some authorities. IV.2 How then would the derivation go? Let T. L. Heath speak for this view: IV.3 To prove that, if there are many, each will be so small as to have no size, Heath explains,

Zeno relied on the infinite divisibility of bodies as evident; assuming this, he easily proved that division will continually give smaller and smaller parts, there will be no limit to their diminution, and [i] if there is a final element, it must be absolutely nothing. Consequently, [ii] to add any number of these nil-elements... to one another, even in infinite number, will give nothing as the total.

Had Zeno followed this line of reasoning, he would have blundered, as can be easily shown: Heath's [i] will do only as a hypothetical whose antecedent must be false for Zeno, since it is contrary to [T] above, and also because the consequent of [i] is false, being contrary to [Q] above. As for Heath's [ii], it would be similarly unobjectionable if taken only as a hypothetical, sc. "if there were final members of zero magnitude, the aggregate magnitude of an infinity of them would indeed be zero." But what would this do to establish the demonstrandum, (our [U]), that the magnitude of each of the many existents is zero? Nothing. To derive this from Heath's [i] and [ii] Zeno, would have to assert the antecedent of [i]; and this he could only do by contradicting, as has just been shown, two things he has previously asserted in BI.IV. 4

But what would this prove? Unless we are prepared to settle matters of historical fact by issuing unlimited credit to our philosophical heroes, we cannot regard the blunder in $j I$ as a sufficient reason for thinking it could not have been Zeno's. We can, however, concede that if he did make such a mistake, it would not have been so arbitary as it appears in Heath's reconstruction; he would not, we may assume, pursue a line of argument providing two good grounds precluding the existence of final elements of null magnitude, and then turn right around and for no reason at all assert their existence. Could there have been any such reason? To see that there could have been we may turn to an argument in Simplicius of uncertain authorship, not included in Diels-Kranz, but listed as a Zeno fragment by Lee and defended by him as genuine. IV.5 Since Simplicius gets it from Porphyry, I shall call it 'the Porphyry text." Here is a fairly literal translation, IV. 6 with referencemarks interspersed:

Parmenides had another argument which was thought to prove by means of dichotomy that being is only one, and that it is without parts and indivisible.

[A] For, he says, if it is divisible, let it have been dichotomized. IV.7 Then

[1] either there will be left certain final, smallest, atomic magnitudes, infinite in number, and the whole will then consist of smallest magnitudes, infinite in number; 
[2] or else it will vanish and be dissolved into nothing, and will then consist of nothing.

These conclusions are absurd. Hence it cannot be divided, but will remain one.

[B] Further, since it is all alike throughout, if it is divisible, it will be divisible, throughout $\left(\pi_{\alpha}^{\prime} v-n\right) I V .8$ alike, not just here but not there ( $\left(\bar{n} \mu \varepsilon^{\prime},-\hat{n} \delta \hat{\imath}\right.$ ov $)$.IV.9. It will be clear that, once again, nothing will remain, but it will vanish, and, if it is to have components, it will consist of nothing. For if any part of it is left over, it has not yet been divided throughout. From all this, he says, it is evident that being will be indivisible, without parts, and one.

Conspicuously absent from this argument is any mention of infinite divisibility. But that the assumption is made at [A2] and [B] is certain. If.10 For since [A] is the case in which the division is finally stopped by "atomic magnitudes," [A2] must be the remaining alternative: no "atomic magnitudes," hence infinite divisibility. The same, a fortiori, at [B], for this takes up where [A2] leaves off, adding nothing except the stipulation that being is "divisible throughout", thereby closing off the [AI] possibility left open before. How then does the writer get to the conclusions of [A2] and [B]? -- His key moves are the opening ones: "Iet it have been dichotomized" at [A]; "let it have been divided throughout at $[B]$. In other words: suppose that the operations which are said to be possible in the hypotheses ("divisible"; "divisible throughout") have been carried through to a finish, or completed. The conclusion which interests us then appears as a necessary condition of this completion: so long as any part of being is left undivided, the division of being has not been completed; it can have been completed only when being has wholly 'vanished.' But what makes the writer so sure that his key moves are authorized? To put in the most blatant form the assumption he is making, let us have him reply:

'Suppose the hypothesis had been instead, "x is mechanically divisible." I would then be obviously authorized to assume that it is logically possible to carry out completely the mechanical division of $x$. By the same token, from "x is infinitely divisible" I am entitled to infer that, on this hypothesis, the completion of the infinite division of $x$ is logically possible.'

What is being assumed here is that the logical (no less than the grammatical) relation of 'infinitely' to 'divisible' is parallel to that which ordinary adverbs like 'mechanically', 'smoothly', 'cheaply', etc., might bear to 'divisible.' The assumption is, of course, mistaken, for it leads to a contradiction: Since 'infiitely" = "endlessly", IV..II and "completion" = "Ending", IV.I2 it follows that the completion of the infinite division of $x$ is logically possible' $=$ 'the ending of the endless division of $\underline{x}$ is logicalizy possible.' But this brings into the open the contradiction that remains concealed even when the assumption is put in the ultra-explicit form of the imaginary argument above, for even there it is far from obvious that the relation of "completion" to "infinitely' is the same as that of "ending" to 'endlessly." How much more plausible the whole argument would be when this assumption itself is masked by excluding 'infinitely' from a place in the explicit premises, as the whole argument of the Porphyry text succeeds in doing. The extent of its plausibility we may judge from the fact that the core of [B] is reproduced point for point in an argument which Aristotle cites IV. 13 as the very one which was "believed to necessitate atomic magnitudes"; IV.I4 and Aristotle talks IV.I5 as though it was so believed by Democritus. 
Zeno too then could have subscribed to the same reasoning; and having reached by this route the conclusion that infinite divisibility entails dissolution into final elements of null magnitude, he could have carried the results over into BI, and could then easily have taken $j I$, contradiction and all, in his stride. All this, if the argument in the Porphyry text is really his. But is it?

Citing it from Porphyry, where, as we saw, it is ascribed to Parmenides, Simplicius remarks: "it is worth considering whether this argument is really Parmenides', and not, as Alexander thinks, Zeno's" (140.23). For opposing the Parmenidean authorship, Simplicius gives an excellent reason: "no such argument figures among the Parmenidean(texts):" IV.16 But when suggesting its derivation from Zeno, all he can offer in support is "that most of our information refers the puzzles from dichotomy to Zeno." IV.I7 This is meager evidence indeed: the cited statement is consistent with the existence of several original 'arguments from dichotomy' by early writers other than Zeno, and for any number of later pastiches. Did Alexander then have a better reason? Not likely, else Simplicius would have mentioned it to strengthen his case. And there is internal evidence against its ascription to Zeno: (1) It argues constructively for the Eleatic thesis that Being is one and indivisible, after the manner of Parmenides and Melissus, not destructively against the non-Eleatic thesis that "there are many," which is the only thing Zeno did when arguing on plurality according to both our primary IV.18 and secondary IV.19 evidence. (2) The form of the arguments is quite different from that of Zeno's extant arguments against plurality, both of which fall very self-consciously into the 'If $\underline{P}$, then $\underline{C}$ and not- $\underline{C}$ ' pattern, the predicates in $\mathrm{C}$ and not-C, being carefully phrased to heighten the felt contrast: so small as to be null and so large as to be infinite at Bl; finite (in number) and infinite (in number) at B3. In the Porphyry text this pattern is altogether absent at [B], while [A] offers alternatives at [1] and [2]. ("either... or...."), not a conjunction ("both... and..."), and makes no effort to exploit the contrast by finding at [2] pat antitheses to the predicates at [1]. With the materials of [A] Zeno would surely have produced a razor-sharp ' $\underline{C}$ and not- $\underline{C}$ ' conclusion from the hypothesis, or even a couple of them, : finite in size and null. in size; infinite in number and null in number. Nor would it have been like him to bluster at [I], saying its conclusion is "absurd", instead of parading its absurdity. What is it, anyhow? None is now visible to the naked eye.

So the case against the ascription of the Porphyry text to Zeno is strong, while that for it could hardly be weaker. IV.20 But this text has at least shown us the only plausible route by which Zeno too would have inferred final elements of null magnitude from infinite divisibility, if he had ever done so: by way of the assumption that "is infinitely divisible" entails "its complete division is logically possible." Let us then scan his other fragments to see if he shows any tendency to take this path in any of them. He certainly does not in the Race-course and Achilles, both of which proceed on precisely the opposite assumption: that their respective series, being infinite, can not be traversed. Nor does he in B3: the number of existents, Zeno argues here, must be infinite "because there are always other (existents) between any (given) existents, and again others between these:" Here too the argument would have been ruined if Zeno thought that this infinite process could be completed. So far, then, as we can judge from his other work, Zeno did not make the assumption that would have led to $[U]$ via $\underline{j I}$. 
We could, therefore, rule against $j I$ by merely availing ourselves of a principle of exegesis analogous to the "innocent if not proved guilty" rule of the common law: given two constructions of a text, both of them equally consistent with the evidence, prefer the one more favorable to the author's intelligence. Such jII would certainly be: it would suppose Zeno to be inferring that $\underline{a}$ is "so small as to have no magnitude" from the conclusion of Sl that a has no magnitude. The inference is harmless to the point of triviality, and Fraenkel's suspicion of "precarious" logic here -.. "Smallness, i.e. Iittle magnitude, can hardly be ascribed to a thing which actually possesses none" (p. 200) -- seems unfounded: One could indeed object to an inference like 'a has no size, therefore it has a very small size," since "very small size $e^{\frac{7}{7}}$ does suggest some finite size, all the more so in the context of BI, where "some size" at $I$ and "size" at 2 are used to mean a finite size. But I can see no good reason" to object to "a has no size, therefore" a is so small as to have no size", "for "no size" in the consequent quite clearly precludes the reservation of a finite size. So logically jII is as impeccable IV.2l as $j I$ was disreputable, and has a sterling claim to the benefit of the doubt. What is more, it has some slight positive evidence in its favor: Simplicius writes as though he believed jII. With both [U] and [not-U] clearly before him -- he starts off by citing it at 139.8-9 -- he refers to Bl (by citation, $14 \mathrm{l} .1 \mathrm{ff.}$ ) only as providing proof of [not-U], infinity of size; IV.22 and since he does not tell us how [U] is proved, but does refer (by paraphrase, 139.18-19) to the proof of nullity of size at Sl, it seems reasonable to assume that he thinks this was the proof of the first horn. To be sure, it remains possible that he misunderstood Zeno's argument. But had he done so, it is more likely that he would have misunderstood it in the direction of $j I$ (since, as we have seen, he is willing to credit Zeno with the text from Porphyry, and hence to believe that Zeno did deduce null size from infinite divisibility). And since his knowledge of the text was better than ours, his apparent interpretation of it in the direction of jII may be allowed to decide in its favor.

\section{(V) The Deduction of Infinity of Size.}

Having exhonerated Zeno from a fallacy in the deduction of [U], it would be pleasant if we could render him the same service in the deduction of [not-U]. This unfortunately is out of the question. That a is "so large as to be infinite" could have been derived, so far as I can see, from nothing but the immediately preceding argument, and only by intercalating the certainly false premise that the sum of every infinite set whose every member has finite size must be infinitely large. V.I Only one proposal to save Zeno from this error is even worth discussing: Fraenkel's, to the effect that apeira could mean here 'indeterminate,' no less than 'infinite," and that Zeno was exploiting the double entendre to make "the conclusion sound far stronger than it really is" (p. 197). But I find this third allegation of slippery logic no stronger than the ones I rejected above. This one can be disposed of on purely linguistic grounds: We do not know of a single case in which apeiron means 'indeterminate in respect of size (or, of number)." When it does mean 'indeterminate," as in a fragment of Philolaus (BII) or in Plato's Philebus ( $23 \mathrm{c} 9 \mathrm{ff.}$ ), it expresses simply lack of form or definiteness in general. Neither in these cases, nor in any other classical text known to me, $\mathrm{V} .2$ is apeiron used as modifier of size or number to mean 'large or small or medium, we don't (or, can't) know which.' 
What we do find is, in poetic or popular, usage, apeiron for 'indeterminately large", i.e. 'vast, enormous. 'V.3 And this, of course, would not save Fraenkel's thesis, for even if we supposed it (as Fraenkel does not) to be the meaning of apeira here, it would convey an inference as fallacious as if it did mean 'infinite': to infer that the sum of the $\underline{b}+\underline{a}+\underline{f}+\ldots$ series is enormously large would be as bad a mistake (indeed, a worse, more whimsical, one) as to infer that it is infinitely large.

There is then no escaping the sense of 'infinite' for apeira, and we must, therefore, reconcile ourselves to the thought that our clever Zeno here walked into a booby-trap. How are we to explain the mishap? The simplest explanation would be that it was due simply to his ignorance of the arithmetical theorem (whose first preserved statement is in Aristotle), V. 4 that the sum of a series will not exhaust a finite quantity, no matter how far the series may be extended, if its terms decrease in constant ratio.V.5 I do not find this a convincing explanation. Zeno's arithmetic, properly used, would surely have taught him all he needed to know in order to explode his fallacy by this method. Thus, if he made $3 / 4$ the ratio of division, he could have seen that when the series had just two terms, $\underline{b}$ and $\underline{d}$, the sum would be $3 a / 4+3 a / 16=15 a / 16 ;$ when it had three terms, $\underline{b}, \underline{\bar{d}}$, and $\underline{\underline{f}}$, the sum would be 63a/64; and that the same thing would happen no matter how many terms he put into his series, the sum being always less than a, since the last term added would never be the whole of the difference between a and the sum of the preceding terms but always $3 / 4$ of that difference. Naturally, there is no means of proving, and no particular reason for assuming, that Zeno did any such figuring. Let us suppose him averse to such calculations or even incapable of them. He could still have satisfied himself on the essential point by simply reasoning as follows: 'Since all the magnitudes included in the series are non-overlapping parts of $a$, their sum will always fall short of the magnitude of a by just that part of a which remains as yet unincluded in the series -- as some part always must, since the series is infinite. ${ }^{\top}$ There is nothing especially recondite about this reasoning, and the gist of it would be intuitively apparent in the simplest of diagrams, such as the one at Section III, above: if Zeno used a two-dimensional figure to represent a, and moved in division from left to right, it would be perfectly clear that his procedure would never allow him to get past the right-hand extremity of $\underline{a}$, or, indeed, to ever get to $a$.

Conversely, we would do well to remind ourselves that knowledge of the Aristotelian theorem did not offer sufficient protection against Zeno's fallacy. Thus Simplicius, who expounds Aristotle's formula quite intelligently in commenting on Physics $206 \mathrm{~b} 3$, solemnly asserts in other contexts that "that [whole] which consists of infinitely many magnitudes would have infinite magnitude:"V.6 Or, to keep closer to the classical era, we have the same idea in Epicurus:

...neither must we allow that [bodies] of finite size may decrease ad infinitum. For once one says that there are an infinite number of bodies, of no matter what size, in a given thing, it becomes impossible to understand how the size of the latter could still be finite. For [each of] the infinitely many bodies has some size; no matter what may be this size, their [aggregate] size would then be infinite.V.7 
There must have been some tacit assumption which would have made it seem obviously true that any collection of an infinite number of sizeable parts would have to be infinitely large: so very obviously, that even someone who knew all about Aristotle's theorem (as Simplicius certainly did, and some of of Epicurus' associates almost as certainly) V. 8 would not think of applying it to the present case, but infer forthwith infinity of size for the container from infinity of number of the parts contained. I cannot imagine what this could be except that the collection had a smallest member. This would be quite sufficient to make the conclusion seem a matter of course: given an infinity of non-overlapping parts the least of which has some finite magnitude, it would be obvious that the aggregate magnitude would be infinite. 'But would not this contradict [T] above?' - Certainly, since 'smallest' entails 'Iast.' But the contradiction need not have been apparent even if carried to the closest proximity with [T]. It could even be imported into the explication of $[\mathrm{T}]$, and still not strike the eye, as e.g. in 'all the members of this series, down to the very smallest, must have some finite size." And if the italicized phrase aroused misgivings, they could be suppressed with, 'the members of the series are arranged in order of decreasing size, so there must be a part smaller than any part,V.9 and this could only be the smallest." The plausibility of this assumption seems to me very great. It expresses the tendency to extrapolate from what remains true of the series so long as it has a finite number of terms to what would would be the case if all its terms were present in it. Zeno's best hope of checking this tendency $\overline{l a y}$ in making the assumption as explicit as possible. Had he actually said, 'the series $\underline{b}+$ $\underline{d}+\underline{e}+\ldots$ must have a last member, ${ }^{\prime}$ his chances of noticing the contradiction with [T] would have immeasurably improved. He threw this chance away when he treated the inference as something much too obvious to deserve a place in his text.

Lacking support in textual evidence, V.10 the suggestion I have made is merely a hypothesis as to why Zeno made the fallacy in the deduction of [not-U]. But that he did make the fallacy is no hypothesis. It is as much of a certainty as any we can hope to reach in such matters. Since there is no trace of a similar error before Zeno's time, he must be reckoned the inventor of this fallacy. And since his arguments had a considerabla currency, he must also be reckoned its most important propagator. It may thus have been his influence that reached down to the end of the fourth century to provide Epicurus with a bad reason for atomism:V.ll It was certainly at work in the midale of that century, for Zeno is mentioned as the source of arguments which led Xenocrates to that metaphysical and mathematical oddity, the doctrine of indivisible lines.V.l2 It is a reasonable presumption, though of this we have no direct evidence, that he also exercised some influence on the founder of the atomic hypothesis, his contemporary, Leucippus. V.13

But on another of his great contemporaries, Anaxagoras, Zeno's arguments fell flat. Anaxagoras' knowledge of Zeno's book can now be more than a general presumption, for some close echoes of Zenonian diction have been recently noticed in two of his fragments. V.14 Acquainted with Zeno's arguments, yet making infinite divisibility a cardinal principle of his physics, Anaxagoras must have certainly rejected Zeno's fallacious inference from it in BI. This is perfectly plain from the very form in which he states his adherence to the principle of infinite divisibility: V.I5 
B3 For of the small there is no smallest, but always a smaller, for it is impossible that what is should not be...

B6 ... Since the smallest cannot exist...

In the italicized words Anaxagoras explicity repudiates that assumption which, if I am right, was just the source of Zeno's fallacy.

(VI) Some Conclusions.

1. Of "Pythagorean" point-atoms, no sign.

It has been held by scholars of the highest eminence, and is still widely believed today, the Zeno's polemic was specially directed against a theory, supposedly held by the Pythagoreans of his time, that the ultimate components of the universe had the indivisibility of geometrical points and the extensive magnitude of physical bodies.V $\perp .1$ Elsewhere I have questioned the existence of trustworthy evidence that the Pythagoreans entertained any such theory at this time.VI.2 Here we may consider Zeno's side of this supposed polemic. From the foregoing analysis of one of his arguments against plurality, what may we learn of its target? -- The refutandum of the whole argument is "many. exist," and what it professes to show, if true, would be true of any existents: none have size, and all have infinite size. The premises used in the deduction are, in the first case, the self-identity and unity of any existent, which no one would have denied; in the second, the capacity to increase other things when attached to them, to decrease them when detached from them, which all nonEleatics would impute to all existents. The scope of the argument then is perfectly general: all being, real or supposed, is its theme. Where then are the famous point-atoms? There is no mention of them or allusion to them in the fragments we have studied, and not once have we found it necessary to bring them into the elucidation of the sense of Zeno's words.

But Aristotle, in a reference to B2, writes as follows:VI.3

Further, (i) if unity itself were indivisible, then, according to Zeno's postulate, it would be nothing. (ii) For, he says, that which makes [something else] no larger, when added, and no smaller, when subtracted, is not an exisitent. (iii) evidently assuming that being is magnitude. (iv) And, if a magnitude, it must be corporeal, for this [has magnitude] in all dimensions VI.4, while other [magnitudes], do make [other things] larger when added in one way but not in another: e.g. a plane [may increase a plane] and a line [may increase a line], but (v) a point and a unit [can increase anything] in no way whatever. (vi) But though his theory is of a low order, and the possibility of an indivisible thing can be justified even to himVI.5 -. for such a thing [sc. a point] when added would increase the number, though not the size -- still, how can a magnitude arise from one, or any number of such [indivisible] things? This would be like saying a line could arise from points.

Now if we did not have the original fragment, we would find it difficult to sort out reportage from inference in this whole passage, and could then have good excuse for invoking Aristotle's witness for talk of the indivisible pointunity in Zeno's argument. Yet even then an attentive reading might have made 
out the difference between (ii), which is clearly credited to Zeno ("he says"), VI.6 and everything after it, since already at (iii) Aristotle is telling us what is impliedVI.7 by the Zenonian doctrine at (ii), without saying that this implication was mentioned by Zeno himself; while at (iv) and $(v)$ we are at a still further remove from the paraphrase at (ii), for these are only implications of (iii).VI.8 Yet it is just this "instructive passage" which Burnet thinks proves that Zeno's first argument against plurality "refers to points."VI.9 Ross too cites ( $v$ ) in this passage as one item of evidence for the view that "what Zeno is attacking is the building up of the world out of points and units;"VI.IO his other item is Simplicius, 99.10, "(vii) But here, at Eudemus says, he [Zeno] refuted the One -- for he speaks of the point as the One:" But this is unintelligible apart from the context, where the "here" refers to the long extract from Eudemus that Simplicius $(97.11$-99.6) has just finished quoting. The relevant lines are, "(viii) but the point he [Zeno] assumed was nothing.VI.Il (ix) For he held that what does not increase [another thing] when added, nor decrease (it) when subtracted, is not an existent" (97.15-16). Here it is quite clear that not even Eudemus claims to be reporting any statement of Zeno's about the point: this Zeno "assumed" ( $\pi \theta_{i v \alpha_{1}}$ ), he says, i.e. must have thought so, since he held $(i x)$. Thus the point unit, which made its first appearance in our texts in Aristotle's argument at (iv) above, continues to accompany the paraphrase of $\mathrm{B} 2$, though still without any claim that Zeno said this or anything else about the point. It is only at (vii) that this distinction rubs off at last, and the explanation, "for he speaks of the point as the One," reads as though Eudemus said that Zeno said that the point is "the One:" But since we have the original of Eudemus's statement we can see that not even he said that Zeno said any such thing. VI.12

\section{Dialectical Histrionics.}

If I had to judge Zeno's character on no other evidence than that supplied by his performance in this argument aginst plurality, my verdict would be: (1) He is not an impostor, even in play: three distinct imputations of sophistry have been examined, and not one of them, I have argued, is sustained by the evidence. VI.13 (2) But he is very much of a showman:VI.14 His theatrical taste is written all over its design. When he reached the end of B2, he had already proved to his satisfaction that, if the many exist, they cannot have size, and that they must have size. This of itself, if valid, would be an ample refutation of the pluralist thesis; hence everything thereafter would be logically supernumerary. But for Zeno this sequel is the climax of the whole argument, contriving the far more spectacular contradiction, "so small as to have no size, so large as to be infinite." Had he been less intent on getting this melodramatic finale, he would have been spared the logical gaffe by which he got it. The mistake was avoidable, since Anaxagoras avoided it without benefit of any interventing improvement in logical or mathematical apparatus.

\section{Advance in Logical Technique.}

But Zeno's argument, for all its faults, marks a great advance in philosophical argumentation, as one can see by comparing it with the only important previous venture in this medium: Parmenides. One part of Zeno's argument, the first six lines of $\mathrm{BI}$, is a brilliant piece of logical exposition, 
incomparably more precise, rigorous, and economical than any surviving fragment of earlier philosophical prose. The architectonics of the whole argument are also impressive. Three distinct inferential sequences are joined to form a unified argument, exhibiting, probably for the first time in a philosophical context, the reductio in its most powerful form, "If $\underline{P}$,

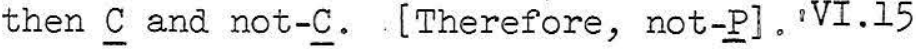

\section{A Substantive Contribution.}

But Zeno reveals more than technical talent in this argument. In its opening part he throws out an idea new to Western philosophy: the incorporeality of Being. VI.16 It is easy to miss its significance. VI.I7 since he exploits it only for dialectical purposes. How great is its value will be apparent if one notes that in this area the vision of the great Parmenides remained blurred and indistinct; and that without this needed clarification the whole of that great metaphysical construction hovers uncertainly on the edge of confusion.VI.18 
Notes.

I. [This paper represents research in progress. Corrections, criticisms, suggestions will be gratefully received by the writer at 131 Pyne Administration Bldg, Princeton, N.J., or at the meeting of the S.A.G.Ph. (Harvard, December 27, 1957) at which it will be discussed.]

2. H. Fraenkel, "Zeno of Elea's Attacks on Plurality," A.J.P. 63 (1942), pp. I ff. and $193 \mathrm{ff}$. I shall refer to this hereafter solely by the author's name. (The same paper, with few changes, has been translated in Fraenkel's Wege und Formen Fruehgriechischen Denkens, Munich, 1955). For references to other studies see Fraenkel, and the commentaries in H.D.P. Lee, Zeno of Elea (Cambridge, 1936), and P. Albertelli, Gli Eleati (Bari, 1939). To these should now be added N.B. Booth, "Zeno's Paradoxes," J.H.S. 77 (1957), Part II, pp. $000 \mathrm{ff}$.

3. History of Greek Philosophy, translated by S. F. Alleyne, London, I88I, I, pp. $614 \mathrm{ff}$.

I.I Commentary on Aristotle's Physics 138.3 ff. To this book I shall refer solely by its author's name.

\section{I.2 Fragmente der Vorsokratiker, 6th ed. (Berlin, 1951).}

I.3 For the correct reconstruction of the order of its various sections see Fraenkel, pp. $17 \mathrm{ff.}$. The same order in Albertelli, op. cit., p. 204.

I.4 Most probably Simplicius' book did not purport to be a complete text of Zeno's original treatise (else why only o i $\mu \alpha 1$ at 99.17? and why appeal to nothing better than the $\pi$ hisin istopi $\alpha$ at 140.24?) Yet Simplicius was confident that he knew at least parts of Zeno's own book. He refers to Zeno's "treatise" at 140.28 (also at 139.5), the same term he used for that of e.g. Parmenides (144.28), Anaxagoras (163.7), and Diogenes (151.25-28).

I.5 A variant text would yield, "If being exists..." But the subject of "exists" in the Diels text followed above is still likely to be "Being" rather than "each of the many": see the context in Simplicius 109.20 110.2 .

\section{I.6 Cf. Plato Meno 77 a 7 .}

\section{I.7 Simpl. 138.3-5 (included under Lee 7)}

I.8 Cf. Alexander ap. Simpl. 127.20-25. Cf. the transition from 'having

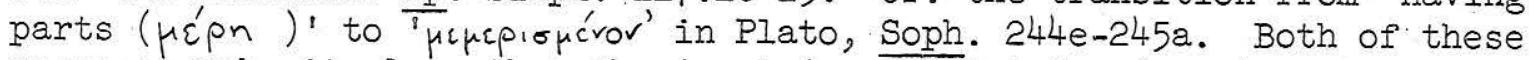
passages make it clear that the 'parts' and 'divisions' envisaged in such arguments are not necessarily physical cuts and do not assume the necessity of intervening wedges to keep one thing apart from another in order to justify the propriety of referring to them as distinct parts of the whole or of the whole being divisible or divided in this way. As will be noticed below (Section III) there is no reference to splits or fissions in the derivation of parts, and parts of parts, at Bl; and there is obviously none in the dichotomies of the Race-Course (Arist., Phys. 233a $21 \mathrm{ff.,239b} 14 \mathrm{ff.}$ ). 
I.9 A reconstruction of it (the probable sense, not the wording) may be of interest: "If (a) there are many, then (b) each of them would have to be one, for (c) the many are a multitude of ones; but (not-b) none of them could be one, for ( $d$ ) each would be divisible ad infinitum, hence (e) each would be infinitely many." Evidence: For (a) as the refutandum of several of Zeno's arguments: Plato Parm. 128d 5-6; Simpl. 139.5. For the form of the reductio: BI sub fin.; B3; Plato Parm. 127e l-2. For 'if (a), then (b), for (c)': Eudemus ap. Simpl. 99.7 (= Lee 6; echoed by Philoponus in Lee 2 and 8; cf. also Plato Parm. 165e 5-7, and Arist. De Gen. et Cor. 325a 9).

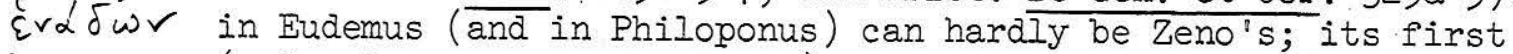
known use (and only one, even by Plato) is at Phileb. 15a: Eudemus is clearly not quoting; and that part of his phrasing which suggests that Zeno argued for the non-existence of any 'one' may be dismissed as careless paraphrasing or misunderstanding, similar to that of Alexander ap. Simpl. 127.20.25. For '(not-b), for (a)': Themistius f. 12.1 (=Lee I). For ' $(d)$, hence $(e)^{\prime}$ : Alexander ap. Simpl. 183.4 but without 'ad infinitum' at (d), and 'infinitely' at (e), which Alexander may have omitted because they are logically pleonastic, though very much in Zeno's style: see below, section (VI) at 2(2). The original of these last two items was clearly not in Simplicius" text, else he would not quote Themistius' paraphrase (139.19) of the first, nor would he remark of the second, 'I think there was no such argument in Zeno's text (99.17).'

\section{I.10 Zeno must have had a fair number of arguments against plurality in his} book ( $40^{\prime}$ in Ptoclus in Parm. p. 694.23 is doubtless a padded figure, but even so a testimony to the large total with which he was credited), and, in spite of his great inventiveness, could hardly have avoided some duplication of vital premises.

II.I Not printed as a direct quotation in Diels, though both the diction and the stylistic turn of the first clause mark it off as Zeno's.

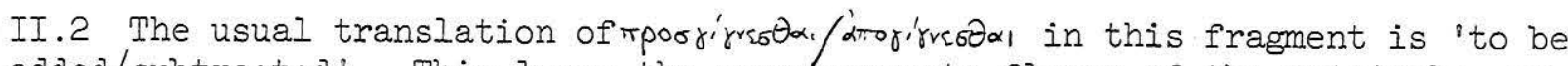
added/subtracted. This loses the more concrete flavor of the original: cf. Melissus B7(4). There is good reason to think these words were never the ordinary terms for 'adding/subtracting': they could not take the active voice, nor supply derivatives for 'addition/subtraction' to compete with mpósorss/apa'prsis

II.3 Cf. Fraenkel, pp. 2l-22, and n. 59.

II.4 "That which has no size" would be the minor, 'nothing", the major, and 'that which would not increase another by attachment to it,' the middle term.

II.5 Other objections to this construction are: (i) We would expect $\varepsilon_{i}^{\prime} \gamma$ 'ap in lieu of $\varepsilon^{\prime} \delta \varepsilon$ at the start of [4]. But $\delta_{\varepsilon}^{\prime}$ can introduce a statement giving the reason for the preceding: Liddeld \& Scott, s.v., I.3. (ii) Since to tposjivopivr has been used at [3] to refer to the existent which has no size (the logical subject of [1], [2], and [3]), one would normally expect àsopivorérou/mposyirotísu at [4] to have the same reference. But in that case the second part of [4] would be a mere reiteration, contrary to Zeno's habitual economy. 
II.6 Even this could have been overcome by changing the order: instead of Sl-B2-B3, he could have made it B2-BI (Iines 1-7)-SI-BI (Iines 7-9); note that $\mathrm{Sl}$ does not invoke any premises which directly contradict anything in $\mathrm{B} 2$ and $\mathrm{BI}$.

III.I Equally possible grammatically is "(it [sc. each of the many] exists)", as in Fraenkel, p. 195 and n. 72. But this makes the "each" in the next clause stylistically repetitious.

III.2 For this construction of $\alpha \dot{u}$ tou , partitive, and referring to see Fraenkel, n. 67. This had already been seen by W. A. Heidel in 1913 (Proc. of Amer. Acad. of Arts and Sciences, vol. 48, p. 724), but has been ignored in both Diels (-Kranz) and the English translations.

III.3 Strictly construed, the grammar of $I$ would yield 'If $[P]$, then [Q and R].' But since Zeno would justify [R] by [Q], the logical sequence has to be as above.

III.4 The reason for the question-marks, if not already obvious, will soon become so.

III.5 See Albertelli, p. 207, for the main pre-1939 references.

III.6 Op. cit., pp. 616-17.

III.7 Pp. 193 ff. Fraenkel's construction is different from Zeller's in so many ways (beginning with the translation), that it may be misleading to think of it is as a version of Zeller's theory. It is that only in respect of assuming that Zeno operates with two terms separate by a third at each step of the argument, rather than with just two contiguous terms.

III.8 Or to 'front' and 'back' parts, assumed in Fraenkel's interpretation . A projection need not be towards the front.

III.9 Zeno's use of the term in this fragment is most probably due to his thinking of the first term in each division as being much larger than its twin. If $\underline{b}$ is much larger than $\underline{c}$, it would be natural to think of $\underline{b}$ as the base and of $\bar{c}$ as a 'projection' from it. I have ignored this point in the accompanying diagram, using the more convenient $1 / 1$ ratio as the principium divisionis.

III.10 That which is said to àréxar at I is termed the rpouxor at $\underline{2}$.

III.Il Though scarcely foreign to his thought or vocabulary. Cf. Siaps-ón at Parmenides B8.22, Jinpniar at Melissus BIO.

III.I2 It is thus evident that the series of divisions, $D_{1}, D_{2}, D_{3}, \ldots$, matches term for term the series of "projecting" parts, $\underline{c}$, $\underline{e}, \underline{g}, . .$. Each is denumerably infinite, and, having a first term, can have no last. 
IV.I A gap in our text is, of course, possible at this point, but there is no good reason to suppose it. That there was none in Simplicius' source is as good as certain, for, to my knowledge, he never presents a broken citation as though it were unbroken in any of his dozens of quotations from the preSocratics. And it is hard to see how the break could have been made by an earlier copyist or editor: Why should anyone want to give the argument through $[\mathrm{T}]$, and then skip the links to the conclusion?

IV.2 E.g. P. Tannery, Pour I'Histoire de la Science Grecque (Paris, 1887), pp. 254-55; T. L. Heath, History of Greek Mathematics I (Oxford, 1921), p. $275 ;$ Lee, op. cit., p. 30. I discuss Heath's construction as the most plausible one. For Tannery's see n. 6, below. Lee's is ingenious, but would, in effect, make [not-U]] a necessary premise for the deduction of [U] .

IV.3 Loc. cit. This is not Heath at his best. He seems to be unaware of the contradiction in the reasoning he imputes to Zeno. I suspect he was misled by Tannery (loc. cit.) to whom he does not refer, but whose very wording he echoes.

IV.4 Tannery's construction (Ioc. cit.) leaves Zeno free from this fallacy, but only by shifting on Zeno's "adversary" the burden of asserting that there are final elements. But if that is the way the "adversary" is going to behave, how did he get past our [T], or even to it: was he so careless as to agree to $[R]$ ?

IV.5 The second in his Zeno fragments. For the defence, see his commentary. Albertelli (op. cit., p. 185) cites it along with Philoponus $80.23 \mathrm{ff}$. (= Lee 3) as examples of "fanciful and partly arbitrary reconstructions of Zenonian reasoning" by later writers.

IV.6 Partly indebted to Lee's.

IV.7 The process here must be exhaustive binary division, getting two parts at the first division, 4 at the second, 8 at the third, $2 n$ at the nth.

IV.8 Tártn also in Aristotle, de Gen. et Cor. (abbreviated to 'GC' hereafter) $316 \mathrm{a} 16 \mathrm{ff}$. and $325 \mathrm{a} \mathrm{8}$, and only in these two passages in Aristotle with this meaning, to my knowledge.

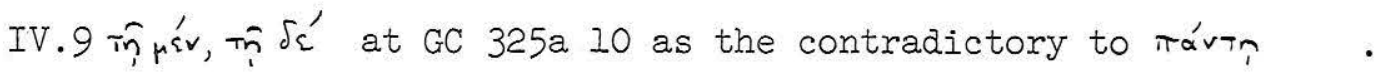

IV.10 At [Al] also, for nothing less than an infinite number of divisions is required to produce an infinite number of these atoms from a single original thing; but that "final" terms do result would also entail that the series of divisions is not infinite. This is a muddle, the worst I have encountered in this inquiry.

IV.II In a sense which has nothing to do with temporal endlessness, but is simply the logical endlessness of a series of divisions (IV.7, above) which can have no last term, since it is denumerable and has a first. 
IV.12 In the same sense, i.e. reaching the final terms of the series of terms produced by the series of divisions. [Al] speaks openly of "final" terms; [A2] and [B] imply the same thing, since their "nothings" are not regarded as existing outside the series (in which case their existence would be logically harmless) but as members of the series, hence necessarily its last members.

IV.13 GC 316a $15 \mathrm{ff.}$; cf. IV. 8, above. The main difference is "body" here in place of "being" in the Porphyry text, and a far more verbose and explicit argument, whose goal is to establish pluralistic atomism, not (as in Porphyry) Eleatic monism. But the structure of the two arguments is the same. This one runs: If a body is "divisible throughout," its complete division is logically possible, but cannot be complete so long as any part remains undivided; hence, when the division has been completed, the body will have been dissolved into extensionless points or bare "nothings" (316a 28). For a better comprehension of this argument, the sense of the difficult line, 316 a 20, should be taken, to be just that indicated at note IV.7, above:

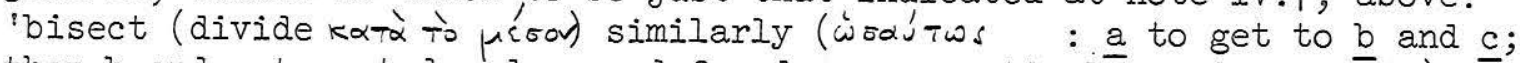
then $\underline{b}$ and $c$ to get, $\underline{\mathrm{a}}$ and $\underline{e}$, and $\underline{f}$ and $\underline{g}$, respectively; and so for $\overline{t h}$ ) and completely Tirai '’dws $\delta_{c}$, i.e.e, until no part is left undivided; Joachim's rendering [the Oxford translation, followed also in the Loeb] "by any other method," is very strained and in any case unnecessary, since a simple translation makes good sense).

IV. 14 GC $316 \mathrm{~b} 35$.

IV.15 Without actually saying so. Cf. GC 316a 14; cf. H. Cherniss, Aristotle's Criticism of Presocratic Philosophy, Baltimore, 1935, p. 113, but note also the striking similarities with GC 325 a 8-10, noticed at notes IV.8 and 9, above, and further that the inference from infinite divisibility to the dissolution of existents into non-existents is endorsed by Epicurus, Ep. ad Hat. 56, and seems to be echoed also by Lucretius, I.746-756.

IV.16 For "texts", not "traditions" ( so Lee, p. 22), to be supplied after iuis

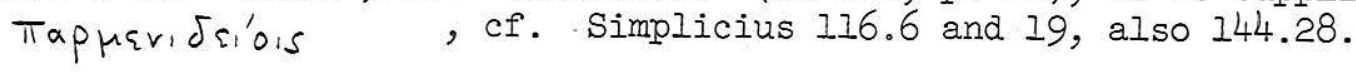

IV.I7 Lee (p. 3I) thinks "Simplicius clinches his argument [for the Zenonian authorship of the Porphyry text] by quoting this argument [B3] from Zeno's own book as being sufficiently similar to the argument in question [that of the Porphyry text] to justify him attributing, it to Zeno." But the subject

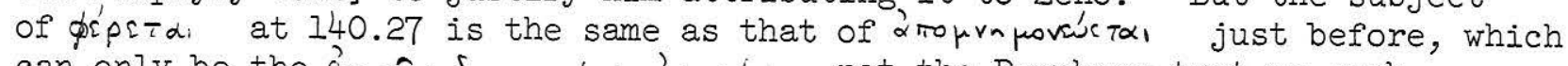

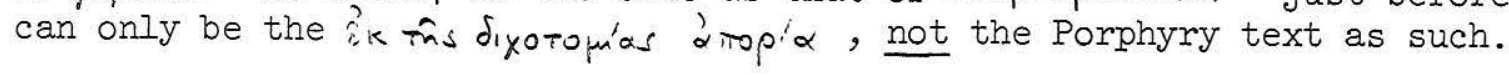

IV.I8 BI, B3.

IV.19 Plato, Parm. 127e ff.; Simplicius 139.5 ff., 14l.10.

IV.20 Its authorship must remain unknown, though we may surely list Melissus as an important source for [B]. He too argued formally for the same demonstrandum (cf. his B9 and B10), and made explicit use (at his B7) of the Parmenidean premise that being is "all alike", from which the key proposition is derived at the start of [B] that being must be "divisible throughout" and not "just here, but not there": both of these expressions occur, as we have seen (IV.8 and 9, above) at GC 325a 3-13, which seems to be principally a report of Melissean doctrine (the initial 
argument, 'no motion, if no vacuum,' is properly his [B7 (7-10)], and the next one, "no plurality if no vacuum" is most likely to be his, since he is the only Eleatic known to have used the non-existence of a vacuum as an explicit dialectical premise).

IV.2I There might still be the objection that "so small as to have no size" is linguistically idiosyncratic. But Zeno does want a special effect here: to make the contrast with "so large as to be infinite" at [not-U] as Ioud as possible. Is it too loud? Not for his purpose; he wants to startle.

IV.22 The strength of this link in the argument would be doubled by Fraenkel's (p. 17) brilliantemendation of $\alpha$ 'ispov for $\alpha \pi \varepsilon^{\prime} \rho \omega r$ of the MSS. at Simplicius 139.15. For then Simplicius' epitome of BI at 139.17-18 would be attached directly to [not-U], instead of merely, as on the present reading, to [Q] . But I am not sure the emendation is correct: the style of ka $\alpha$ ripor etc. seems a little too spry for Simplicius.

VI. Also, of course, the unobjectionable premise that the magnitude of a equals the sum of the series $\underline{b}+\underline{a}+\underline{\underline{f}}+\underline{h}+\ldots$ (cf. the diagram at III, above).

V.2 Fraenkel (Ioc. cit.) also refers to Aristotle's use of apeiron at Phys. 3.6 to refer to a convergent series. But here apeiron is predicated of the series (not of its sum, as it would have to be in our fragment) and does mean "infinite."

V.3 Good example in Liddell and Scott, s.V. B.I.

V.4 Phys: 3.6, 206b 7-9. For the best translation and explanation see T. I. Heath, Mathematics in Aristotle (Oxford, 1949), p. 106.

V.5 There is, of course, nothing in the premises of Zeno's argument to require (a) that the $\underline{b}+\underline{d}+\underline{f}+\ldots$ series decrease in constant ratio, or (b) that the assumed magnitude of a be finite. But both (a) and (b) are consistent with the premises, so that if their addition sufficed to defeat the conclusion (as it does) the dialectical force of the whole argument would be ruined.

V.6 Physics 142.14; cf. also 459.23-24, 460.2-4, 462.3-5. From ibid., 459.25-26 it would appear that Eudemus held the same view. Eudemus, needless to say, is a competent historian of mathematics, and so is simplicius himself (cf. pp. 60 to 69 of his Physics).

V.7 Ep. ad Hdt. I have yet to find a satisfactory gloss on this remarkable passage.

V.8 Though I can find no evidence on this topic, it seems to me incredible that Epicurus" circle would not include some moderately competent mathematicians.

V.9 Which would even be true if taken to mean, 'given any part, there is always a smaller." In spite of verbal appearances, the two statements would be contraries. Cf. Bertrand Russell, Our Knowledge of the External World, Revised Edition, London, 1926, pp. 141-42. 
V.10 But see note V.16, below.

V.II I suspect that the equally fallacious argument at Lucr. I.615-622 also comes from Zeno: its affinity to his B3 is obvious, and it can be recast into the same, 'If $P$, then $C$ and not-C', form: 'If any part, a, of the universe, $\underline{u}$, is infinitely divisible, then the number of parts in a and $\underline{u}$ is equal (sinceinfinite in both) and unequal (since $\underline{u}$ has all the parits of $\underline{a}$ and also all the parts of parts other than a.).

V.12 Ps.-Arist., De Iineis Insec. 968a $18 \mathrm{ff.,} 969 \mathrm{a} 26 \mathrm{ff.}, 969 \mathrm{~b}$ I6ff. All these references are to the Race-Course. But 968a 3-4 looks like a reference to our Bl, though without ascription to Zeno. Cf. also Philoponus, Phys. $84.15 \mathrm{ff}$. The testimony of Alexander ap. Simplicius $138.10 \mathrm{ff}$, and of Simplicius himself, $140.13 \mathrm{ff}$. and $142.16 \mathrm{ff}$, is not so clear.

V.13 Cf. also the rejection of infinite divisibility implied in Antiphon's theory that an inscribed polygon of a very large number of sides would equal the circumference of the circle (Simplicius $54.20 \mathrm{ff} . ;$ Heath, op. cit., pp. $22 \mathrm{ff.}$ ) and Democritus alleged (but more doubtful) mathematical ('no less than physical) rejection of infinite divisibility (Heath, op. cit., pp. 179 ff., and also his Mathematics in Aristotle [Oxford, 1949], pp. 79-80, where he seems to have been won over by Luria's learned, but not entirely dependable, paper, to which he refers on $p .79)$. Zenonian influence on Antiphon or Democritus is plausible, though there is no direct evidence for it. Anyhow it is certain that anyone who thought Zeno's argument valid would have to abandon infinite divisibility in mathematics -- a point seldom realized by historians (e.g. Cornford, Plato and Parmenides [London, 1939], p. 6I) who seem to think that Zeno's paradoxes could be evaded by merely abandoning the infinite divisibility of physical magnitudes.

V.14 J. E. Raven, "The Basis of Anaxagoras" Cosmology," Class. Quart. 48 (1954), at pp. 126-28.

V.I5 We are fortunate in having these original fragments, for from Simplicius (461.7-9) one might have gathered that Anaxagoras did make the same fallacy. But note that Simplicius does not profess to be paraphrasing at this point. but only to be drawing an inference Guvrociv ) from the foregoing. He assumes that the inference he would draw (sc. that everything is infinitely large: note V.6, above) from the premise that everything has an infinite number of parts would also be drawn by Anaxagoras. The only thing in Anaxagoras? fragments that might lend color to this imputation is the last sentence of B3, and it is significant that Simplicius did not cite it in support of his intepretation. I would translate, "in relation to itself each thing is both great and small," and would interprete: when we take a thing just by itself, the determinations 'large: or 'small' become matters of indifference; a grain of sand is small only by comparison, say, to a stone; taken by itself there is no more reason for calling it 'small' than 'large.'

V.16 That Anaxagoras should be so emphatic on this point (note that 'no smallest' at $B 3$ is strictly unnecessary: the sentence might as well have read simply 'of the small there is always a smaller" as the next one does read "and of the large there is always a larger") suggests that he thought this was the source of Zeno "s fallacy. 
VI.I The best statement of the theory is still that of its originator, Paul Tannery (op. cit., chapter on Zeno). For influential adherents: Burret, Early Greek Philosophy, 3rd ed., (London, 1920), pp. 310 ff.; Cornford, op. cit., pp. $58 \mathrm{ff.;.H.} \mathrm{Cherniss,} \mathrm{op.} \mathrm{cit.,} \mathrm{p.} 43$ and pp. 155-161. Raven (op.cit,, p. 126) speaks of this view, with some reason, as now "generally accepted." But contra, e.g. G. Calogero, Studi Sull'Eleatismo (Rome, 1932),

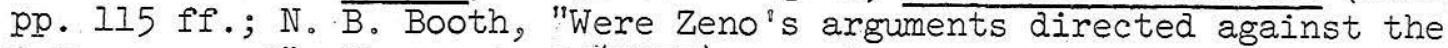

Pythagoreans?" Phronesis 2 (1957), pp. $95 \mathrm{ff}$.

VI.2 Gnomon 25 (1953), pp. 31-32.

VI.3 Met. 100 Ib 7-19. I have made liberal use of the oxford translation.

VI.4 I am adopting Fraenkel's (p. 18) deletion of $\%$ at line 11 . Without the deletion the sense would be still the same, but its expression would be violently elliptical: "for this has being in all dimensions (sc. all three of the dimensions which it would be possible for being to have on the assumption that it is magnitude.)?

VI.5 I.e. even if we were to assume that what Zeno says at ( $i i$ ) is true.

VI.6 A perfectly adequate paraphrase of the closing part -- [4] at (II), above -- of our B2. The substitution of "added/subtracted" for "attached/detached" in the original (see note II.2, above) is scarcely culpable in this context.

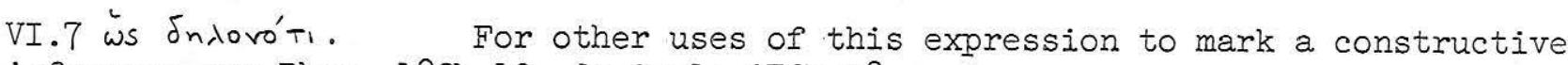
inference see Phys. 189b 10, de Caelo $279 \mathrm{~b} 28$.

VI.8 Similarly at ( $i$ ) Zeno is not represented as having said that unity, if indivisible, would be nothing, or even that what is indivisible would be nothing. "Zeno's axioma" is clearly what Zeno assumed, i.e. (ii): cf. Cherniss" excellent paraphrase, op. cit., p. 43, n. 165. -- As for "theory" at (vi), it refers to (ii)+ $(\mathrm{iii})+(\mathrm{iv})+(\bar{v}), \mathrm{i} . e$. to what Zeno "says" and what follows from it.

VI.9 Op. cit., p. 317.

VI.10 Commentary on the Metaphysics, I, p. 246. But Ross does not explain why he thinks this is the case. Shortly before $(p, 245)$ he appears to be recognizing that (ii) is all that Aristotle ascribes directly to Zeno.

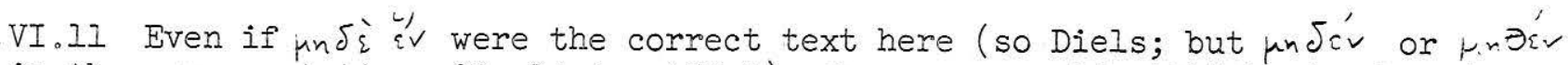
in the same quotation, Simplicius 139.1), the sense would still be "nothing" ("not even one").

VI.I2 But even if Eudemus were professing to be giving us at (viii) information of what Zeno said, the gift would be of dubious value, since Eudemus seems to be following not Zeno's text but Aristotle's paraphrase: his reference to "point"

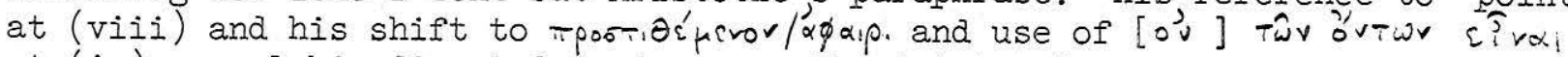
at (ix) reveal his direct dependence on the Aristotelian passage.

VI.13 I.e., that of the fragments. As for the secondary evidence, the best of it, Plato's, is ambiguous: at Parm. 128ab Plato puts the gravity of Zeno's argument on a level with that of Parmenides himself; at Phdr. 26ld ff. he 
associates Zeno with the orator who makes the same things take on contrary appearances, and thus seems to think of him as an artificer of deception, whence Cornford (op. cit., pp. 67-68) infers that "Plato seems to have thought of him as a mere sophist." But note that Plato does not impute to Zeno intentional deception or deliberately sophistical arguments, and that in calling him the "Eleatic Palemedes" associates him with inventors (cf. Rep. 522d, Laws 677d), not charlatans. The reference to Zeno as a professional sophist (taking fees) is only in I Alc. (II9a).

VI. 14- Here I meet Fraenkel (pp. 193, 206) half-way.

VI. I5 The reductio is, of course, also Parmenides" stand-by; but neither does he cast his arguments in the form which would exhibit the fatal consequences of the refutandum as a pair of contradictory propositions.

VI.16 On the above reconstruction of $\mathrm{S} I$, 'no existent has size' would be true for Zeno, since it follows from [ZI], [Z3], and [Z4], not one of which he would have reason to doubt. This conclusion gets some added support from the fact that it would preserve consistency with the pattern of argumentation suggested at Phdr. 26ld 7-8, which may be expanded and rephrased in the light of Parm. $127 \bar{e}$ I-2 as 'If there are many, then each would be both homogeneous and heterogeneous, both one and many, both at rest and in motion." It will be noticed that the first term in each of the contradictory pairs -- "homogeneous ( '́po:a ; of. Parm. B8.22 and Mel. B7.I)," "one", "at rest" -- would be a true predicate of Eleatic Being. So would the first term of the corresponding pair -- 'no size and infinite size' -- in the present argument.

VI.17 I too have missed this prior to the present study: I ascribed the innovation to Melissus (Gnomon 25 [1953], pp. 34-35. Since Zeno's book was written in his youth ( Parm. 128d), it is reasonable to assume that it preceded any writings by Melissus.

VI.18 I cannot attempt to defend here my view that the incorporeality of Being is entailed by Parmenidean doctrine, but is not asserted by Parmenides, probably because he himself did not clearly see the entailment. 